\title{
Projects Delay Factors of Saudi Arabia Construction Industry Using PLS- SEM Path Modelling Approach
}

\author{
Ismail Abdul Rahman ${ }^{1}$, Nashwan Al-Emad ${ }^{2}$ and Sasitharan Nagapan ${ }^{1}$ \\ ${ }^{1}$ Faculty of Civil and Environmental Engineering, Universiti Tun Hussein Onn Malaysia, 86400 Parit Raja - Batu Pahat, Johor, Malaysia \\ ${ }^{2}$ Sariya Contracting Company Ltd, Novotel Business Park, Tower 2, 3rd Floor, Dammam,-Khobar Highway, Post Box: 4486, Al Khobar \\ 31952, Kingdom of Saudi
}

\begin{abstract}
This paper presents the development of PLS-SEM Path Model of delay factors of Saudi Arabia construction industry focussing on Mecca City. The model was developed and assessed using SmartPLS v3.0 software and it consists of 37 factors/manifests in 7 groups/independent variables and one dependent variable which is delay of the construction projects. The model was rigorously assessed at measurement and structural components and the outcomes found that the model has achieved the required threshold values. At structural level of the model, among the seven groups, the client and consultant group has the highest impact on construction delay with path coefficient $\beta$-value of 0.452 and the project management and contract administration group is having the least impact to the construction delay with $\beta$-value of 0.016 . The overall model has moderate explaining power ability with $\mathrm{R}^{2}$ value of 0.197 for Saudi Arabia construction industry representation. This model will able to assist practitioners in Mecca city to pay more attention in risk analysis for potential construction delay.
\end{abstract}

\section{Introduction}

Structural Equation Model (SEM) using Partial Least Square (PLS) technique is also known as PLS-SEM path modelling. It is a second generation of multivariate statistical analysis which simultaneously evaluates multiple variables. SEM comprises of two types that are covariance based SEM known as CB-SEM and PLS path modelling known as PLS-SEM. Principally, PLS-SEM is used for developing a structural relationship model while CB-SEM is for confirming the structural relationship of the developed model [1]. PLS-SEM path model consists of two components. First component is structural model also known as inner model and the second component is measurement models called outer models. Outer model displays the relationships between the independent variables and manifest variables while the inner model displays the relationships between the independent and dependent variables. Variables also called constructs are not directly measured while manifests also called indicators or items are the directly measured proxy variables that contain the raw data [2].

\section{PLS-SEM model}

A hypothetical model of delay factors for Saudi Arabia construction industry was constructed where it consisted of 37 delay factors (manifests/indicators/items), 7 groups of the factors (independent constructs/variables) generated through factor analysis technique and one dependent variable which is the construction delay. These delay factors were identified through rigorous literature view and verify by experts in pilot study. The model displays the concept/theory with its key elements (i.e. constructs) and cause-effect relationships (i.e. paths) [2,3].

\subsection{Model's data}

Input data for the model were derived from the questionnaire survey involved 100 respondents who are working in Mecca city construction industry. They rated each of the 37 factors using 5-point likert scale on degree of significance toward construction delay. These yielded 3700 data used to develop the PLS structural model for causative factors of construction delay in Mecca city. These data are recorded in sav format of excel software and then converted into the .csv format by using (save As) function in the software. Once the data is converted, the following step is to create a new project sheet in SmartPLS software for developing a model based on the hypothetical model and the converted (.csv) data file is imported into the model.

\subsection{Model's construction}

Construction of the model in SmartPLS software involved several steps and amongst the important steps are 
constructing the model according to the hypothetical model, assigned name of constructs (groups), connecting the independent variables/groups with dependent variable (construction delay) and assigning the manifests(factors) to the respective independent variables. Once all the manifests are assigned to the respective constructs then the colour of the constructs will change from red to blue and the manifest displayed in yellow colour.

Constructed model comprised of 7 groups (independent variables) for the 37 delay factors (manifests) where the collected data were assigned to them. These 7 groups are converged to one dependent variable. The dependent variable needs input data with single item that is either each of the factors are causing delay or otherwise ( 1 or 0 respectively). Prior to this modelling, it was determined that all the factors are causing delay which means value of 1 for each factor was applied to the model. Based on this information, the model was constructed as Fig. 1.

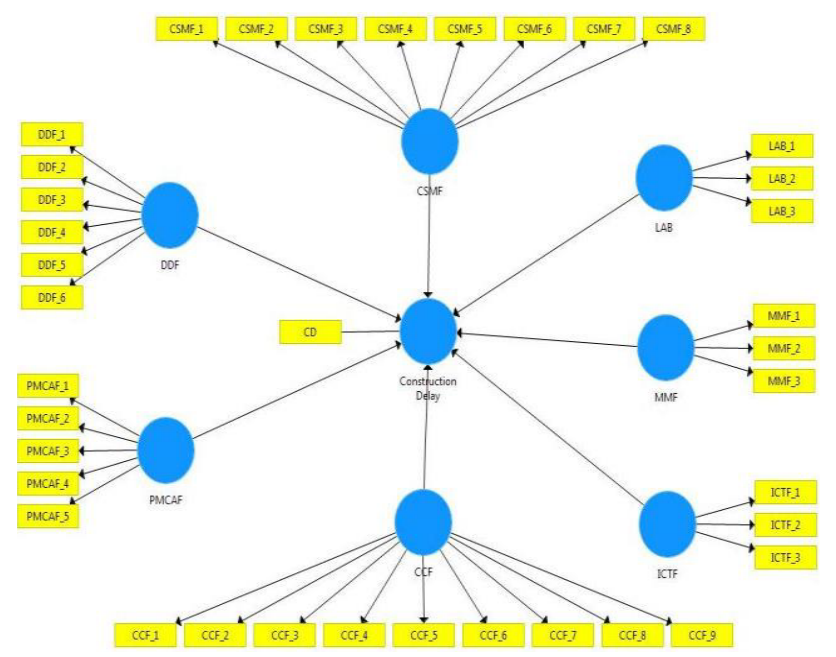

Figure 1. The developed PLS model.

Based on Fig. 1, each of the 7 independent variables consists of several factors/manifests which are as clarified below:

1) CSMF is contractor's site management related factor group which consisted: CSM1 for Poor qualification of staff assigned to the project, CSM2 for Shortage of professionals in organization, CSM3 for Inadequate Contractor's experience, CSM4 for Inaccurate estimation of project duration during the bidding stage, CSM5 for Incompetent subcontractors, CSM6 for Delay in preparation of shop drawings, CSM7 for Delay in preparation and submission of materials samples and CSM8 Difficulties in financing project by contractor.

2) $\mathrm{CCF}$ is client and consultant related factor group which consisted: CCF1 is Delay in approving of change orders, CCF2 is Frauds practice among the parties involved, $\mathrm{CCF} 3$ is Inadequate consultant experience, CCF4 is Lack of coordination with authorities, CCF5 is Slow decision-making process, CCF6 is Difficulty in accessing the site, CCF7 is Delay in obtaining permits from Municipality, CCF8 is Delay in approving shop drawings and CCF9 is Delay in progress payment.
3) DDF is design and documentation related factor group which comprised: DDF1 is Mistakes in design documents, DDF2 is Changes in design documents, DDF3 is Late in approving of design documents, DDF4 is Inadequate details provided in drawings, DDF5 is Delays in producing design documents, and DDF6 is Insufficient data collection and survey before design.

4) PMCAF is project management and contract Administration related factors group which consisted: PMCAF1 is Poor contract management, PMCAF2 is Unrealistic contract duration, PMCAF3 Poor site management and supervision, PMCAF4 is Improper planning and scheduling of the project and PMCAF5 is lack of teamwork.

5) MMF is material and machinery related factor group which comprised: MMF1 for late procurement of materials, MMF2 for Delay in materials delivery and MMF3 for Delay in equipment delivery.

6) LAB is labour related factors croup which consisted: LAB1 for Low productivity level of labour, LAB2 for Unqualified workforce and LAB3 for Shortage of manpower.

7) ICTF is the information and communication related factor group which comprised: ICTF1 is Poor communication between parties; ICTF2 is Poor coordination between parties and ICTF3 is Ineffective monitoring and controlling of the project progress.

After the model has developed, simulations on the model are carried out using PLS algorithm function for calculating the loadings on each manifest as well as estimating the structural model's path coefficients. The software generates various required parameters for model assessment as shown in Fig. 2.

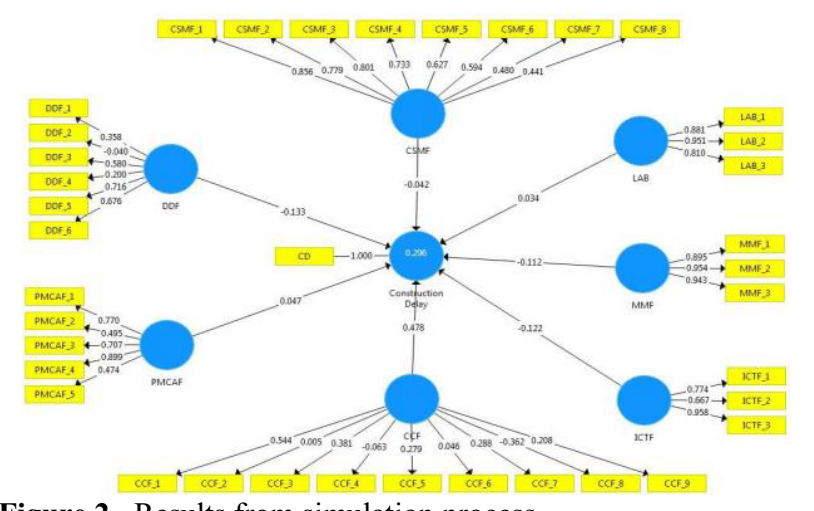

Figure 2. Results from simulation process.

Fig. 2 shows the generated values for assessment at two stages which are at measurement level for internal consistency to ensure the adequacy of the relationships between independent and manifest variables and also at the structural model for examining the relationship between dependent and independent variables. Required assessments for the measurement and structural model were carried out on accordance to [4], [5] suggestions.

\section{Assessments on measurement model}

Assessment of measurement model (outer model) is to check internal consistency of the model whether 
relationships between independent and manifest variables are adequate. It is carried out in two stages; first stage is checking the model performance after each iteration of computation (Individual item reliabilities and convergent validities) and the second stage is the analysis on the model's final iteration (discriminant validities).

\subsection{Model's performance}

After each simulation process, the measurement model needs to be assessed for its convergent validity and individual item reliability values which were generated concurrently. Three parameters used to determine convergent validity are Average Variance Extracted (AVE), Convergent Validity (CR) and Cronbach's alpha. Required threshold values for the parameters are Average Variance Extracted (AVE) $\geq 0.5$, Convergent Validity $(\mathrm{CR}) \geq 0.7$ and Cronbach's alpha $\geq 0.7$ [6, 7, 8]. For individual item reliability, each manifest is considered significant if its loading value is more than $0.5[1,4]$. However, if any of manifests having loading value less than 0.5 , it should be omitted and dropped. Then the computational process and model performance are reassessed in several iterations until it achieved the stated values for convergent validity and individual item reliability. For this study 6 iterative processes were carried out before reaching reliability for all the factors. A total of 11 weak factors/manifests were omitted and left 26 significant manifests which are reliable for the final outputs. After iteration 6, the required threshold values for the average convergent validity are Average Variance Extracted (AVE) $=0.658$, Composite Reliability (CR) $=0.870$ and Cronbach's Alpha (Alpha) $=0.820[6,8]$. This means that the model has achieved the required validity process. The generated parameters values for the 7 groups generated from the final iteration as shown in Table 1 .

Table 1. Convergent validity of measurement model.

\begin{tabular}{|c|c|c|c|}
\hline \multirow{2}{*}{ Group/ Construct } & \multicolumn{3}{|c|}{ Convergent validity parameters } \\
\cline { 2 - 4 } & $\begin{array}{l}\text { AVE } \\
(\mathbf{0 . 5})\end{array}$ & $\begin{array}{c}\text { CR } \\
(\mathbf{0 . 7 )}\end{array}$ & $\begin{array}{c}\text { Alpha } \\
(\geq \mathbf{0 . 7 )}\end{array}$ \\
\hline $\begin{array}{c}\text { Material and Machinery } \\
\text { Related Factors }\end{array}$ & 0.867 & 0.951 & 0.929 \\
\hline $\begin{array}{c}\text { Contractor's Site } \\
\text { Management Related } \\
\text { Factor }\end{array}$ & 0.553 & 0.879 & 0.842 \\
\hline $\begin{array}{c}\text { Design and Documentation } \\
\text { Related Factor }\end{array}$ & 0.569 & 0.839 & 0.784 \\
\hline $\begin{array}{c}\text { Information and } \\
\text { Communication } \\
\text { Technology Related } \\
\text { Factors }\end{array}$ & 0.654 & 0.847 & 0.827 \\
\hline $\begin{array}{c}\text { Labour Management } \\
\text { Related Factors }\end{array}$ & 0.778 & 0.913 & 0.861 \\
\hline $\begin{array}{c}\text { Client and Consultant } \\
\text { Related Factors }\end{array}$ & 0.543 & 0.822 & 0.757 \\
\hline $\begin{array}{c}\text { Project Management and } \\
\text { Contract Administration } \\
\text { Related Factors }\end{array}$ & 0.640 & 0.841 & 0.739 \\
\hline Average & $\mathbf{0 . 6 5 8}$ & $\mathbf{0 . 8 7 0}$ & $\mathbf{0 . 8 2 0}$ \\
\hline
\end{tabular}

Tablel presents the convergent validity values for all the groups/independent variables. All the values are above the threshold and these indicate that the measurement model has achieved convergent validity. Since all the manifests attained loading factor equal or more than 0.5 , then the measurement model has achieved individual item reliability. Thus, the measurement model had achieved the consistency of all the manifests toward the construction delay.

\subsection{Discriminant validity assessment}

Next step of measurement assessment for PLS-SEM model is to assess discriminant validity which reflects the extent to which a construct is truly distinct from other constructs by empirical standards [4]. It involves CrossLoading and Average Variance Extracted analysis [4, 6, 8] which are as follows:

\subsubsection{Cross loading analysis}

It is to examine that each manifest variable should have higher loading correlation with their relative independent variable. Specifically, an indicator's outer loading on the associated construct should be greater than all of its loadings on other constructs [4]. Generated values of this model found that each manifest variable is higher in their relative independent variable than other independent variables as in Table 2 . This indicates that the model has achieved its discriminant validity.

Table 2. Analysis of cross-loading factors.

\begin{tabular}{|c|c|c|c|c|c|c|c|}
\hline \multirow{2}{*}{ Factor } & \multicolumn{7}{|c|}{ Independent variables/construct } \\
\cline { 2 - 8 } & CCF & CSMF & DDF & ICTF & LAB & MMF & PMCAF \\
\hline CCF1 & 0.926 & 0.337 & 0.383 & 0.115 & 0.213 & 0.345 & 0.126 \\
\hline CCF3 & 0.754 & 0.375 & 0.397 & 0.344 & 0.345 & 0.307 & 0.358 \\
\hline CCF5 & 0.584 & 0.394 & 0.430 & 0.226 & 0.297 & 0.298 & 0.316 \\
\hline CCF7 & 0.637 & 0.516 & 0.318 & 0.158 & 0.288 & 0.602 & 0.234 \\
\hline CSMF1 & 0.351 & 0.863 & 0.265 & 0.466 & 0.502 & 0.552 & 0.457 \\
\hline CSMF2 & 0.374 & 0.795 & 0.227 & 0.484 & 0.442 & 0.402 & 0.355 \\
\hline CSMF3 & 0.316 & 0.814 & 0.219 & 0.452 & 0.431 & 0.428 & 0.337 \\
\hline CSMF4 & 0.504 & 0.740 & 0.358 & 0.276 & 0.429 & 0.434 & 0.275 \\
\hline CSMF5 & 0.438 & 0.629 & 0.411 & 0.333 & 0.442 & 0.506 & 0.358 \\
\hline CSMF6 & 0.216 & 0.577 & 0.384 & 0.354 & 0.325 & 0.303 & 0.414 \\
\hline DDF1 & 0.517 & 0.351 & 0.599 & 0.192 & 0.275 & 0.201 & 0.387 \\
\hline DDF3 & 0.455 & 0.224 & 0.777 & 0.164 & 0.348 & 0.287 & 0.454 \\
\hline DDF5 & 0.333 & 0.320 & 0.822 & 0.252 & 0.373 & 0.283 & 0.446 \\
\hline DDF6 & 0.349 & 0.371 & 0.797 & 0.123 & 0.388 & 0.259 & 0.259 \\
\hline ICTF1 & 0.295 & 0.378 & 0.274 & 0.774 & 0.364 & 0.296 & 0.608 \\
\hline ICTF2 & 0.305 & 0.299 & 0.240 & 0.667 & 0.316 & 0.165 & 0.597 \\
\hline ICTF3 & 0.170 & 0.553 & 0.166 & 0.958 & 0.543 & 0.318 & 0.574 \\
\hline LAB1 & 0.245 & 0.450 & 0.411 & 0.463 & 0.881 & 0.266 & 0.436 \\
\hline LAB2 & 0.295 & 0.586 & 0.459 & 0.552 & 0.951 & 0.473 & 0.568 \\
\hline LAB3 & 0.342 & 0.441 & 0.346 & 0.380 & 0.810 & 0.576 & 0.368 \\
\hline MMF1 & 0.378 & 0.474 & 0.293 & 0.332 & 0.438 & 0.895 & 0.363 \\
\hline MMF2 & 0.425 & 0.596 & 0.329 & 0.325 & 0.439 & 0.954 & 0.367 \\
\hline MMF3 & 0.404 & 0.506 & 0.323 & 0.298 & 0.476 & 0.943 & 0.342 \\
\hline PMCAF1 & 0.211 & 0.379 & 0.399 & 0.511 & 0.427 & 0.235 & 0.771 \\
\hline PMCAF3 & 0.375 & 0.469 & 0.399 & 0.445 & 0.403 & 0.258 & 0.712 \\
\hline PMCAF4 & 0.137 & 0.410 & 0.365 & 0.607 & 0.469 & 0.371 & 0.905 \\
\hline
\end{tabular}

\subsubsection{Average Variance Extracted (AVE) analysis}

It is to check the correlation amongst the independent variables for adequate discriminant validity. It is also known as the Fornell-Larcker criterion and it is the second and more conservative approach to assess discriminant validity of PLS-SEM model. It compares the square root 
of the AVE values with the independent variable correlations. Specifically, the square root of each construct's AVE should be greater than its highest correlation with any other construct [4]. The correlations amongst independent variables for this model generated from this analysis are shown in Table 3. This indicates that the diagonal correlation values of the independent variables are higher than non-diagonal values and this satisfies the discriminant validity of the tested model.

Table 3. Analysis of Average Variance Extracted (AVE).

\begin{tabular}{|c|c|c|c|c|c|c|c|}
\hline & \multicolumn{7}{|c|}{ Independent variables / Construct } \\
\cline { 2 - 9 } & CSMF & DDF & LAB & MMF & PMCAF & CCF & ICTF \\
\hline CSMF & 0.743 & & & & & & \\
\hline DDF & 0.401 & 0.754 & & & & & \\
\hline LAB & 0.569 & 0.466 & 0.882 & & & & \\
\hline MMF & 0.576 & 0.342 & 0.482 & 0.931 & & & \\
\hline PMCAF & 0.511 & 0.464 & 0.537 & 0.379 & 0.800 & & \\
\hline CCF & 0.451 & 0.466 & 0.324 & 0.435 & 0.267 & 0.737 & \\
\hline ICTF & 0.550 & 0.222 & 0.541 & 0.335 & 0.658 & 0.238 & 0.808 \\
\hline
\end{tabular}

\section{Structural model assessments}

Once the groups' manifests are reliable and valid, the next step is to assess the results of structural model. This involves examining relationship between dependent variable with independent variables. It is carried out by checking the strength of impact path of independent variable to the dependent variable and also the explanatory power $\left(\mathrm{R}^{2}\right)$.

\subsection{Impact strength}

Impact strength of variables toward to the dependent variable is assessed using path coefficients or $\beta$-value $[1,9$, 10]. A structural model can be considered acceptable if all the $\beta$-value is above 0.1 [4]. According to [8], the higher $\beta$-value shows the stronger impact of a predictor independent variable on the dependent variable.[4] mentioned that the path coefficients have standardized values between -1 and +1 , where the estimated path coefficients close to +1 represent strong positive relationships (and vice versa for negative values) that are almost always statistically significant. The closer the estimated coefficients are to 0 , the weaker the relationships. And the very low values close to 0 are usually non-significant. According to [4], the signage of $\beta$-value whether it is positive or negative is not a concern because the impact of path is the absolute value of the $\beta$ value. The results of structural model obtained from SmartPLS are presented in Fig. 3.

Fig. 3 presents the path co-efficient ( $\beta$ values) of each path which was found as -0.223 for CSMF, -0.157 for DDF, -0.016 for PMCAF, 0.452 for CCF, -0.116 for ICTF, -0.168 for MMF and 0.060 for LAB. These path coefficient values of the model substantiates that $\mathrm{CCF}$ (Client and consultant group) has the highest co-efficient value of 0.452. However the PMCAF (Project Management and Contract Administration group) is having the smallest co-efficient value of -0.016 which indicates that PMCAF group is giving the least impact to the construction delay. Thus, it can be concluded that
Client and consultant group of factors has the strongest impact toward the construction delay.

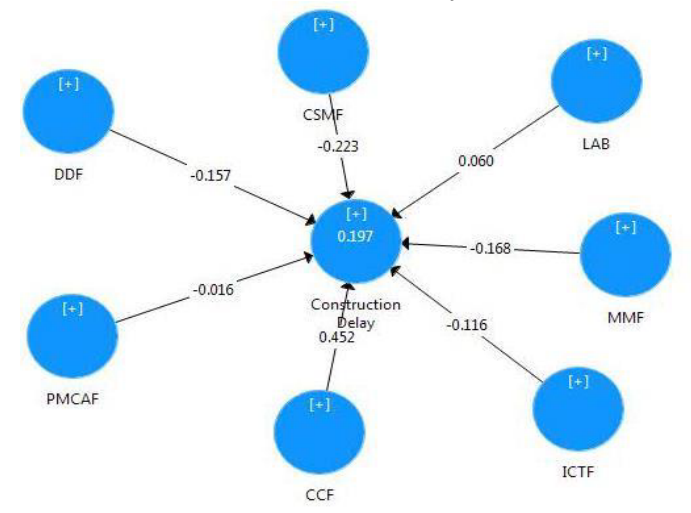

Figure 3. Path coefficients values $(\beta)$ of structural model.

\subsection{Explanatory POWER}

Explanatory Power is to examine the overall ability of the model in representing the impact of independent variables toward the dependent variable. [4] stated that the most commonly used measure to evaluate the structural model is the coefficient of determination $\left(\mathrm{R}^{2}\right.$ value). The indicator used to describe the explanatory power is the model's coefficient of determination which is $\left(\mathrm{R}^{2}\right)$ value $[1,8,6]$. According to [11], a model can be assessed as substantial if $\left(\mathrm{R}^{2}\right)$ equal or more than 0.26 , moderate if $\left(\mathrm{R}^{2}\right)$ equal or more than 0.13 and weak if $\left(\mathrm{R}^{2}\right)$ equal or less than 0.02. In this study the result of developed model is as illustrated in Fig. 3 which shows that $\left(\mathrm{R}^{2}\right)$ is 0.197 . This means that the developed model has moderate explaining power in representing the impact of the 7 groups of factors toward the construction delay (CD).

\section{Conclusions}

This study has examined 37 factors that contribute to construction delay in Saudi Arabia construction industry using PLS-SEM modelling in SmartPLS software. The developed PLS-SEM path model comprised of these factors in 7 groups which contribute to construction delay is to show graphical representation of relationships of construction delay factors. Assessment on the model found that in the outer model all the manifests in the model are reliable and valid and for the inner model, it was found that the client and consultant group is the most dominant path with $\beta$-value 0.452. In contrast, Project Management and Contract Administration group is having the least impact to the construction delay with $\beta$-value of 0.016. Finally, the overall model has moderate explaining power ability to generalize the model for Saudi Arabia construction industry representation. This model will be helpful to persons who are involved in Mecca construction industry in analysing risk for delay and also researchers in the field of construction.

\section{Acknowledgment}

The authors are grateful to University Tun Hussein Onn Malaysia for supporting this research. Furthermore, the 
authors are thankful to construction practitioners who are working in Mecca city for their contributions and providing comprehensive and important information.

\section{References}

1. Memon, A.H., Rahman, I.A., Akram, M., Ali, N.M., Significant factors causing time overrun in construction projects of Peninsular Malaysia, Modern Applied Science, Canadian Center of Science and Education, 8,(4), pp. 16-28, (2014).

2. C. M. Ringle, M. Sarstedt, and E. A. Mooi, Response Based Segmentation Using Finite Mixture Partial Least Squares Theoretical Foundations and an Application to American Customer Satisfaction Index Data. In R. Stahlbock et al. (eds.), Data Mining, Annals of Information Systems, pp. 19-49, (2010).

3. R. Fellows, and A. Liu, Research Methods for Construction. 3rd ed. Wiley-Blackwell: Utopia Press, (2008).

4. J.F.Hair, G.T.M.Hult, C.M.Ringle, and M.Sarstedt, $A$ Primer on Partial Least Squares Structural Equation Modeling (PlS-SEM). United State of America: SAGE Publications, pp. 95-198, (2014).

5. J. Henseler, C. M. Ringle, and R. R. Sinkovics, "The Use of partial least Squares Path modeling in
International Marketing", Advances in International Marketing, 20, pp. 277-319, (2009).

6. S. Akter, J. D'Ambra, and P. Ray, "Trustworthiness in mHealth Information Services: An Assessment of a Hierarchical Model with Mediating and Moderating Effects using Partial Least Squares (PLS)", Journal of the American Society for Information Science and Technology, 62, pp. 100-116, (2011).

7. J. F. Hair, C. M. Ringle, and M. Sarstedt, "PLS-SEM: Indeed a Silver Bullet", The Journal of Marketing Theory and Practice, 19(2), pp. 139-152, (2011).

8. A. A. Aibinu, and A. M. Al-Lawati, "Using PLSSEM technique to model construction organizations' willingness to participate in e-bidding", Automation in Construction, 19, pp. 714-724, Feb. (2010).

9. [9] W. W. Chin, The partial least squares approach for structural equation modeling, In: Marcoulides, G.A. (Ed.), Modern Methods for Business Research. Lawrence Erlbaum Associates, London, 295(2), pp. 295-336, (1998).

10. N. Urbach, and F. Ahlemann, "Structural Equation Modeling in Information Systems Research Using Partial Least Squares", Journal of Information Technology Theory and Application, 11(2), pp. 5-40, (2010).

11. J. Cohen, Statistical power analysis for the behavioral sciences (2nd ed.), Hillsdale, Lawrence Erlbaum Associates, NJ, (1988). 